\title{
The detection of delirium in the I CU: An important aspect of care
}

\author{
Jonathan Harroche, Lyne St-Louis, Martine Gagnon \\ Jewish General Hospital, Canada. \\ Correspondence: Lyne St-Louis. Address: Jewish General Hospital, Canada. Email: Istlouis@jgh.mcgill.ca \\ Received: March 21, 2014 \\ Accepted: July 8, 2014 \\ Online Published: July 23, 2014 \\ DOI : 10.5430/jnep.v4n9p135 \\ URL: http://dx.doi.org/10.5430/jnep.v4n9p135
}

\section{Abstract}

Background: Up to $80 \%$ of mechanically ventilated ICU patients develop delirium. Unfortunately, delirium is underestimated and thus, under-recognized by health care's providers. The use of a delirium screening tool has been proven efficient to promptly recognize patients suffering of delirium and to quickly intervene. Also, educational activities have been proven essential to ensure appropriate prevention, identification and treatment of delirium.

Methodology: The goal of this innovative project was to develop and implement an educational activity on delirium to facilitate the implementation of the Richmond Agitation-Sedation Scale (RASS) and Confusion Assessment Method for the ICU (CAM-ICU) in the ICU of a Canadian university teaching hospital. The educational activity consisted in a 45 minutes teaching session on delirium, the RASS and the CAM-ICU scales, which was followed by a six weeks mentoring of nurses and clinical follow-up of ICU patients. The project was led by an undergraduate nursing student as part of an internship and supervised by the Intensive Care Unit’s Clinical Nurse Specialist and Nursing Education Consultant.

Principal findings: A total of 80 nurses and many members of the interdisciplinary team benefited from the educational activity. In addition, nursing expertise in screening for delirium was recognized by the multidisciplinary team and delirium was systematically addressed during the daily medical rounds. The student leading the project was providing support, guidance and mentoring as needed. As reported by the staff, the support received facilitated the successful implementation of the delirium screening tool, the Confusion Assessment Method for the ICU (CAM-ICU). In addition, it helped the team members to implement interventions to prevent and treat delirium that were tailored to the patient's needs.

Conclusion: Early detection of delirium allows the initiation of prompt treatment thus reducing its negative impact and improving quality of care. Educational activities are important to help achieve these standards.

\section{Key words}

Delirium, ICU, Confusion Assessment Method for the ICU, Richmond Agitation-Sedation Scale, Staff education

\section{I ntroduction}

Thousands of patients presenting with complex illnesses and co-morbidities are admitted yearly in Intensive Care Units (ICU) around the world. Most of the time, their clinical condition is so critical that they frequently require highly specialized care to keep them alive and ensure a return to adequate quality of life. The complexity of their health situations is such that these patients have a high risk of developing many complications, including delirium. As a matter of fact, 
delirium affects $60 \%$ to $80 \%$ of mechanically ventilated patients in the Intensive Care Unit (ICU) ${ }^{[1-5]}$. Unfortunately, delirium is often under-recognized by health care professionals, including nurses. Screening is usually done in a subjective manner without the use of validated tools ${ }^{[6]}$. The Society of Critical Care Medicine recommends routine monitoring of delirium in ICU patients ${ }^{[7,8]}$. Screening and early treatment of delirium can prevent many complications and significantly reduce morbidity. It can reduce not only ICU length of stay but overall hospital length of stay, as well as the associated $\operatorname{costs}^{[9]}$. The Canadian ICU Collaborative, in partnership with the national campaign Safer Healthcare Now have recently put a lot of emphasis on reducing delirium. The Confusion Assessment Method for the Intensive Care Unit (CAM-ICU) is a validated tool with a high level of sensitivity and specificity for the detection of delirium in ICU patients ${ }^{[7,10]}$. It has also been shown that, after nurses have received the appropriate teaching, they have the required skills to thoroughly use this screening tool ${ }^{[11]}$.

Consequently, a university teaching hospital in Montreal, Canada, decided to improve patient's quality of care by adopting the Richmond Agitation-Sedation Scale (RASS) to assess patient sedation level and the Confusion Assessment Method for the ICU (CAM-ICU) to facilitate the detection of delirium by nurses. In order to facilitate the implementation of the RASS and CAM-ICU tools, an undergraduate nursing student has planned, prepared and implemented a training program on delirium for nurses working in the ICU, as part of an internship project in nursing.

The purpose of this article is to increase awareness of delirium: its pathophysiology, risk factors, epidemiology, social and economic impact. The current practices to detect and prevent delirium are explained. Subsequently, a description of the setting where the project took place, the implementation of an educational activity on delirium as well as the implementation process of the Richmond Agitation-Sedation Scale (RASS) and the Confusion Assessment Method for the ICU (CAM-ICU), will be presented. A post-intervention follow-up, the outcomes, a description of the impact of the project and the difficulties encountered are discussed. Finally, suggestions for nursing practice are also issued.

\section{Literature review}

To fully describe the concepts surrounding the theme of delirium, an extensive research on the website www.uptodate.com, was conducted. In addition, many search tools like Medline, CINAHL, Embase, Maestro, PubMed and others were consulted. The following keywords: Delirium, RASS, CAM-ICU, and ICU were used to ensure the relevance of the articles obtained. An analysis of the publications was then performed. The literature focusing on delirium, more specifically on the pathophysiology, risk factors, epidemiology, financial and social impact, current practices and prevention of delirium were used to support the present project.

\subsection{Pathophysiology}

Delirium is a condition that is characterized by a disturbance of the level of consciousness and attention, combined with cognitive or perceptual disturbances that cannot be explained by pre-existing co-morbidities such as dementia. It also develops over a short period of time, usually a few hours to a few days, and signs tend to fluctuate during the day. Some elements of the patient's medical history, physical assessment or laboratory results can help identify some risk or contributing factors. Indeed, delirium may be the direct result of one or more than one cause ${ }^{\text {[12] }}$. Intoxication or withdrawal of medication or recreational drugs, electrolytes imbalances, conditions such as sepsis, or even hearing or visual impairment often contribute to delirium ${ }^{[3,12,13]}$.

Delirium can be further classified into three categories, hyperactive, hypoactive or mixed delirium. The manifestations of hyperactive delirium are agitation, restlessness, and aggressive behaviors toward staff and family members, as well as attempts to remove medical equipment or life sustaining therapies such as mechanical ventilation ${ }^{[3,13,14]}$. Because of its dramatic clinical presentation, hyperactive delirium is the form of delirium most likely to be recognized by health care providers and therefore the one with a better prognosis ${ }^{[3,13,15]}$. 
Hypoactive delirium has a much more subtle clinical presentation leading to under recognition and can be misdiagnosed with other medical conditions like depression. Patients with hypoactive delirium present apathy, a flat affect, withdrawn attitude, decrease responsiveness, lethargy, and even slowed motor skills ${ }^{[3,13]}$.

Finally, a patient suffering from mixed delirium will present features of both hyperactive and hypoactive delirium which will fluctuate during the day ${ }^{[14]}$. In all forms of delirium, patients can also have visual or auditory hallucinations ${ }^{[16]}$.

\subsection{Incidence}

Delirium is a common morbidity for ICU patients as it affects $60 \%$ to $80 \%$ of mechanically ventilated patients ${ }^{[1-5]}$. In the non-mechanically ventilated, the incidence is significantly lower and is found to be between $20 \%$ and $50 \%{ }^{[17]}$. In comparison, the overall incidence in a hospital affects about $30 \%$ of patients ${ }^{[18]}$. More specifically, Peterson, Pun, Dittus, Thomason, Jackson, Shintani, \& Ely ${ }^{[19]}$, in 2006, lead a prospective cohort study which included 614 critically ill patients admitted to a medical ICU of a tertiary care university teaching hospital. Their results showed that among patients who developed delirium during the ICU hospitalization, $1.6 \%$ suffered of hyperactive delirium which made this category the rarer type of delirium. Hypoactive delirium accounted for $43.5 \%$, which is worrisome considering that its subtle clinical presentation contributes to under recognition by nurses ${ }^{[20]}$. Moreover, Pun and Ely ${ }^{[15]}$ cited an article from Meagher and Trzepacz ${ }^{[21]}$, which revealed that hypoactive delirium was underdiagnosed $66 \%$ to $84 \%$ of the time. Finally, mixed delirium was the most common type with an incidence of 54.9\%.

\subsection{Risk factors}

There are several risk factors that may increase the incidence of developing delirium in the ICU patient's population. These can be separated into two categories: predisposing risk factors and precipitating risk factors ${ }^{[13]}$. Predisposing risk factors are defined by risk factors present at time of patient's ICU admission and are therefore, less modifiable. Allen \& Alexander ${ }^{[13]}$ listed: baseline dementia, advanced age, depression, injury severity, chronic illnesses and co-morbidities, tobacco and alcohol use as well as visual and hearing impairments as being predisposing risk factors. Van Rompaey, Elseviers, Schuurmans, Shortridge-Baggett, Truijen, \& Bossaert ${ }^{[22]}$ have also identified that daily consumption of alcohol and smoking are important predisposing risk factors contributing to the development of delirium. In addition, Ouimet et $a l .{ }^{[2]}$ in a prospective study done with 820 ICU patients found that delirium was associated with some predisposing risk factors such as hypertension, alcoholism and higher APACHE II scores. Furthermore, these researchers discovered that the risk of developing delirium increased by $4.9 \%$ per APACHE II score. Moreover, Chang, Tsai, Lin, Chen, \& Liu ${ }^{[23]}$, in a retrospective chart review of 288 patients who underwent cardiac surgery, identified four independent post-operative risk factors as predictors of delirium: cardiogenic shock, hypoalbuminemia, acute infection and a hematocrit less than $30 \%$. In addition, kidney failure, left ventricular ejection fraction (LVEF) less than 30\% and atrial fibrillation were pre-operative co-morbidities also associated with an increased incidence of delirium ${ }^{[23-25]}$.

Precipitating risk factors also called iatrogenic risk factors, are often modifiable ${ }^{[3,9]}$. Allen \& Alexander ${ }^{[13]}$ have listed medications, dehydration, acute infection, sepsis, seizures, hypernatremia, withdrawal syndromes, and metabolic disturbances, as the most common iatrogenic risk factors. Medications most commonly implicated in ICU delirium are: benzodiazepines, opioid analgesics, antihistamines, metoclopramide, promethazine, $\mathrm{H}_{2}$ antagonists, and corticesteroids ${ }^{[13]}$. Among these medications benzodiazepines are by far the class of medication most involved with delirium in critical care ${ }^{[2,3,26]}$. Furthermore, Van Rompaey et al. ${ }^{[22]}$, in a multicenter study done with 523 patients, studied risk factors for delirium subdivided into four categories: characteristics, chronic pathology, acute illness and environmental factors. Among iatrogenic risk factors related to acute illness, they identified that the utilization of indwelling catheters such as urinary catheters, nasogastric and orogastric tubes, as well as, central venous catheters were highly associated with delirium which corroborates the study of Inouye, Zhang, Jones, Kiely, Yang, \& Marcantonio ${ }^{[27]}$. As part of the environmental iatrogenic risk factors, they identified the following: isolation measures, lack of visitors or social stimulation, use of physical restraints, no visible sun light, and transfer from another ward. Finally, sleep deprivation is also another important risk factor, especially in the critical care patient population ${ }^{[15]}$. 


\subsection{I mpact of I CU delirium}

Delirium has a significant impact on the patient, family and health care system. The social impact of delirium is multidimensional. Thomason et al. ${ }^{[5]}$, in a prospective cohort investigation of 261 patients, had the objective to determine the relationship between delirium and outcomes among non-ventilated ICU patients. Among their results, they found that patients with delirium had a $29 \%$ risk of prolonged ICU length of stay and $41 \%$ risk of increased hospital length of stay. Similarly, their study demonstrated a mortality rate of $19 \%$ among patients who had an episode of delirium versus $6 \%$ among those who did not develop such a complication. Furthermore, a research that studied the correlation between the number of days patients suffered from delirium and one year mortality post ICU hospitalization showed a mortality rate of $50 \%$ for patients who were hospitalized for at least 5 days in the ICU and suffered from delirium for 3 days ${ }^{[28]}$.

From a morbidity perspective, delirium has a significant impact on the cognitive functions and quality of life post hospital discharge ${ }^{[29,30]}$. In fact, patients who acquire delirium in the ICU require a longer rehabilitation and convalescence period. In addition, patients with delirium are less likely to return home and have a poorer functional outcome ${ }^{[31]}$. More specifically, Balas and collaborators ${ }^{[31]}$, in a prospective observational cohort study of 114 patients, determined the association between delirium and the following variables: complications in ICU, functional ability and discharge destination. Results showed a significant association between delirium and complication rates $(p=.001)$. More specifically, $31.6 \%$ of patients suffered a complication during the ICU stay. It was also shown that $61.3 \%$ of delirious patients were unlikely to return home and $67.7 \%$ had a decline in functional status. For patients who did not suffer from delirium, these results were respectively $20.5 \%$ and $43.6 \%$. Moreover, Inouye, et al. ${ }^{[27]}$ reported that $11.8 \%$ of patients presented delirium at time of hospital discharge. They subsequently identified five predictive risk factors for delirium at time of discharge: dementia, vision impairment, functional impairment, high co-morbidities and the use of physical restraints during hospital episodes of delirium.

Delirium has also a tremendous impact on the family and support system of the patient. Manifestations of delirium such as aggressive behaviors, hallucinations, lethargy, and attempts to remove catheters can increase family distress ${ }^{[14,16]}$. In addition, caregivers often have to take time off work and get involved in the care of their loved ones; some even have to resign from their jobs. This puts caregivers at an increased risk for burnout ${ }^{[3]}$.

Delirium also impacts the health care system in terms of resource management and associated costs. As previously demonstrated, delirium increases the ICU and hospital length of stay leading to a higher utilization of resources at time of discharge as many patients will be transferred to long-term care facilities ${ }^{[5,32,33]}$. A study conducted by Milbrandt et al. ${ }^{[34]}$ showed that on average, an episode of delirium in the ICU may increase ICU cost by $40 \%$ and hospital costs by $30 \%$.

\subsection{Current practices}

Even though the incidence of ICU delirium is high, health care professionals underestimate it. This is supported by a study led by Rice, Bennett, Gomez, Theall, Knight, \& Foreman ${ }^{[35]}$ using a convenience sample of 167 nurses and 170 medical surgical patients which showed that nurses failed to recognize delirium $75 \%$ of the time. Similarly, Ely, Stephens et al. ${ }^{[36]}$, conducted a survey using a convenience sample of interdisciplinary team members that included: 753 physicians, 113 nurses, 13 pharmacists, and 12 physician assistants, 8 respiratory care practitioners, and 13 other professionals. As part of their findings, $78 \%$ of respondents acknowledged that delirium was underdiagnosed. Despite this fact, these researchers discovered that only $40 \%$ of the health professionals surveyed were regularly screening patients for delirium and no more than $16 \%$ regularly used a screening tool validated in the literature such as the CAM-ICU. A Canadian cross-sectional mail survey with 448 Physicians, among which 273 completed the questionnaires, conducted by Mehta et al. ${ }^{[6]}$ in Ontario, showed, that among other things, $49 \%$ of respondents assessed patients' sedation level with a validated tool and only $3.7 \%$ of them used a screening tool for delirium in their ICUs. Specifically for nurses, a paper/Web-based survey conducted by Devlin, Fong, Howard, Skrobik, McCoy, Yasuda, \& Marshall ${ }^{[37]}$ with 601 nurses working in 16 ICUs was able to demonstrate that only $13 \%$ to $53 \%$ of nurses assessed the presence of delirium in their patients. This variation in results depended greatly on the academic nature of the hospital site. Among the respondents who declared that they were 
routinely assessing for delirium, only $47 \%$ actually used a validated screening tool such as the CAM-ICU. In addition, the study showed that the majority of nurses who were using a validated tool (53\% versus $13 \%)$ were employed in university teaching hospitals.

The lack of screening can be explained in several ways. First, there is the lack of knowledge regarding delirium as mentioned above. In addition, nurses working in the ICU often rely on hemodynamic monitoring and advanced technology to complete a thorough patient assessment ${ }^{[37]}$. Also, there is a false belief that patients who present with delirium are always hyperactive. This results in a lower diagnostic rate of the more common hypoactive delirium ${ }^{[20]}$.

Researchers have identified various factors explaining the lack of delirium recognition and screening. Among others, there is the inherent difficulty in communication for the mechanically ventilated patients ${ }^{[13]}$. Other contributing factors to underdiagnosing delirium include: hypoactive delirium presentation, age over 80 years, vision impairment and pre-existing dementia ${ }^{[20]}$. Furthermore, Olson ${ }^{[14]}$ and Rice et al. ${ }^{[35]}$ identified lack of knowledge and education about delirium as being obstacles to accurate diagnosis by the health care professionals.

\subsection{Prevention of delirium}

Given the high incidence of delirium in the ICU and its many adverse effects, it is of utmost importance that nurses, as well as the interdisciplinary team members, not only screen patients for delirium but also intervene to prevent its occurrence. Health care professionals must remember that delirium is rarely the result of a single risk factor. An interdisciplinary approach targeting a variety of precipitating factors has been proven efficient ${ }^{[9,38]}$. That is why many best practice recommendations have been published and are all included in the ABCDE bundle ${ }^{[39]}$. Daily sedation interruption is an important suggestion as the use of sedatives has been identified as one of the major risk factors for delirium ${ }^{[9]}$. Following the recommendation of the Society of Critical Care Medicine ${ }^{[8]}$, it is the nurse's responsibility to assess and maintain the level of sedation appropriate to the patient's clinical condition and thus avoid over or under sedation. It has been shown that maintaining an appropriate level of sedation helps reduce the risk of complications, including delirium ${ }^{[9]}$. Furthermore, Vasilevskis et al. ${ }^{[9]}$ proposed a systematic approach to reduce ICU length of stay and simultaneously decrease delirium incidence. Interventions proposed included physiotherapy and early mobilization of the patient, even when mechanically ventilated, and the implementation of a program of cognitive rehabilitation. Sleep deprivation is also another well recognized risk factor for delirium ${ }^{[40]}$. The care team should create an environment to promote sleep during night-time. Simple interventions such as reducing ambient noise, diming lights and regrouping care to reduce sleep interruptions have been proven efficient in the prevention of delirium ${ }^{[42]}$. Prophylactic administration of antipsychotic drugs such as haloperidol is not recommended in the prevention of delirium. However, these drugs have been proven efficient in reducing the duration and severity of delirium in combination with non-pharmacological interventions ${ }^{[3]}$. Conversely, a study conducted by Steiner ${ }^{[38]}$, showed a significant reduction in the incidence of delirium in elderly patients over 65 years old undergoing arthroplasty who had received $5 \mathrm{mg}$ of olanzapine pre and postoperatively. The 26\% decrease in the incidence of delirium in this population is very encouraging and deserves more attention.

The constant presence of nurses at the patient's bedside has an important role to play in detecting and preventing delirium ${ }^{[14,20]}$. However, Inouye and collaborators ${ }^{[20]}$ reported that when the CAM-ICU screening tool is used by undertrained nurses, delirium is frequently unrecognized. Furthermore, in order to achieve the gold standard in delirium management, Rice and collaborators ${ }^{[35]}$ recommend the implementation of delirium educational activities and mentoring for nurses and other interdisciplinary team members. The educational program must however be multi-strategic. It should include a combination of different teaching methods such as: awareness campaigns, didactic educational sessions, videos, clinical-reasoning case scenarios and one-on-one clinical situation discussions. By facilitating the translation of theory into practice, key interventions can be put in place to improve prevention, recognition and appropriate interventions regarding delirium by ICU staff ${ }^{[3,37]}$. Regular audits should also be considered to ensure that proper screening and prevention is continuously being done. It is important to recognize that these educational activities might initially increase 
staff burden. However, it is important to reinforce with the staff that by implementing these strategies, the incidence of delirium will decrease and will ultimately ease and improve care ${ }^{[3,20]}$.

\section{I nnovation/ Project description}

The project was conducted in a Canadian urban university teaching hospital. This hospital provides general and specialized care to over 67,000 patients in the emergency room and more than 24,800 inpatients. The ICU has 22 beds. In the fiscal year of 2012-2013, the ICU admitted over 1000 patients, $48 \%$ of whom were post cardiac surgery, $18 \%$ other surgeries and $34 \%$ medicine and oncology ${ }^{[41]}$. ICU patients are cared for by a dynamic interdisciplinary team composed of physicians, nurses, respiratory therapists, physiotherapists, dieticians, pharmacists, a social worker, a speech and language pathologist and an occupational therapist.

This innovative project was conducted as part of an internship in the ICU and supervised by the department's Clinical Nurse Specialist and Nursing Education Consultant. This project consisted of the first phase of a larger endeavor: the implementation of the ABCDE bundle. The original aspect of the current work is reflected by the implementation of the RASS, as a sedation assessment tool, and the CAM-ICU, as a screening tool for delirium. Before the project took place the nursing staff did not consistently screen patients for delirium which is consistent with the literature. In addition, nurses screening for delirium did not use a validated tool and although they were using a sedation scale, they were not using the RASS to assess their patient's sedation level.

This innovative project benefited the ICU team and ultimately the patients. The educational activity consisted of a 45 minute teaching session on delirium, followed by a six week mentoring and clinical follow-up of ICU patients. The teaching sessions were provided in the day, evening and night shifts to a total of 80 nurses. As recommended by Pun and Boehm ${ }^{[3]}$, the student received an intensive training on delirium and sedation assessment, in order to become a resource person for the unit. He also referred to the CAM-ICU user guide ${ }^{[43]}$ and various sources of literature to prepare for the teaching sessions. The power point presentation included theory on pathophysiology and incidence of delirium, RASS, CAM-ICU and interventions to prevent and treat delirium. A 6 minute video was also used to demonstrate the proper utilization of the CAM-ICU. This video was developed by Vanderbilt University Hospital in Nashville, Tennessee. It was created by the sponsors of the original CAM-ICU authors ${ }^{[44]}$.

Following the teaching sessions, a period of supervision and guidance was conducted to ensure that the screening tools, the RASS and the CAM-ICU, were used appropriately and that the results obtained by the nurses were accurate. RASS and CAM-ICU screening tools were plasticized and placed in all patients' charts to be used as a reference by nurses. Furthermore, a binder containing CAM-ICU documents in languages other than English or French were also made available for staff. Simultaneously, ICU patients who developed delirium were closely followed. Identification of patient's risk factors, assessment of delirium using the CAM-ICU, sedation practices and the interventions put in place were collaboratively revised. In addition, emphasis was also put on minimizing the use of physical restraints and central nervous system depressant medications. Non-pharmacological alternatives were also considered and recommendations were made. The knowledge gained has allowed nurses to provide better care to their patients in collaboration with the interdisciplinary team and their families.

The institution where the project took place uses the McGill model of nursing and promotes family-centered care. In accordance with this philosophy, family members were involved in the project. More often than not, family members did not have a good understanding of delirium and felt helpless. Working in close collaboration with them, explaining the interventions they could do with their loved-one such as, reorienting the patient, reading the newspaper, displaying familiar objects or pictures, helped the families gain some control over the situation. A meeting was also planned with the families when a patient presented delirium. At these meetings, the nature of the delirium and the therapeutic approach was discussed with the family. Questions on delirium were answered as clearly as possible to dispel any misunderstanding or 
misconception. In addition, a care plan was collaboratively developed enhancing the family's involvement in their lovedone's care.

\section{Results}

Prior to the intervention, health care professionals were not systematically screening patients for delirium. Subjective criteria such as agitation and lack of cooperation were used to consider whether or not the patient was delirious. Table 1 Delirium screening pre and post intervention. The lack of screening with a validated tool caused delirium to be undetected for many patients, which is consistent with the literature ${ }^{[3]}$.

The educational activity increased nurses' knowledge about delirium: Pathophysiology, incidence, types of delirium (hypoactive, hyperactive, mixed), risk factors, interventions and the impact of delirium on the patient, family and health care system. In addition, nurses learned that the utilization of a validated tool such as the CAM-ICU ensures a reliable detection of patients presenting delirium, which in turn, allows a rapid initiation of interventions to treat delirium and ultimately improve patient care. More specifically, nurses learned how to assess the patient's sedation level using the RASS and how to assess the four key features of delirium: Fluctuation in mental status, inattention, disorganized thinking, and altered level of consciousness using the CAM-ICU.

A total of 80 nurses attended one of the educational sessions and benefited from the mentoring period. In addition, many ICU Attending Physicians and residents participated in a teaching session. The interdisciplinary team had also been informed on the focus of delirium. Furthermore, delirium is now part of the ICU orientation of residents and nurses. Moreover, following the teaching sessions, delirium became part of medical rounds. Every morning, physicians inquired about patient RASS and CAM-ICU scores. At times, the patient's nurse had not yet had the opportunity to apply the CAM-ICU. In these situations, residents and medical students took the opportunity to administer the screening tool themselves. As the nursing student leading the project was also present during these rounds, he was able to provide appropriate coaching to all staff present. At the end of the student's internship, a brief audit was conducted on a total of 20 patients to determine the compliance with the RASS and CAM-ICU tools. Results showed that $100 \%$ of patients' level of sedation was screened with the RASS scale. Among these patients, only two had a sedation level of -3, which was appropriate to their medical condition. It is important to mention that the CAM-ICU tool is difficult to apply to patients that have a RASS score of -3 or -4 and that it is only appropriate to use this tool with patients that have a RASS of -2 to +4 . Among the 18 patients to whom the CAM-ICU could be applied, 94\% (17/18) were screened for delirium on a daily basis and $83 \%$ were screened once per shift. It was reinforced with the health care professionals that delirium can fluctuate during the day and that it is important to screen for delirium on each shift. Further audits are needed to measure the compliance with the utilization of the RASS and CAM-ICU. In addition, a mechanism is required to measure the incidence of delirium.

To facilitate the successful implementation of new screening tools such as the CAM-ICU, it is important to offer the appropriate support, guidance and mentoring. Nurses reported several cases where it was difficult to use the CAM-ICU. In most of these situations, the nursing student that led the project, in collaboration with the Clinical Nurse Specialist, was able to help the nurse use the delirium scale despite the challenging clinical situation. For more complex cases, the CAM-ICU team at Vanderbilt University Hospital in Nashville Tennessee, was contacted by email. With their assistance, it was possible to determine how to optimally address the clinical situation. To ensure confidentiality, these challenging clinical situations will not be discussed in this article.

Finally, adjustments to the Therapeutic Nursing Plan (TNP), initially made by the student in consultation with the patient's nurse, facilitated not only a better continuity of care but ensured that care was provided according to the appropriate context such as hypo or hyperactive delirium or presence of specific risk factors. In addition, the care plan was further 
adjusted collaboratively with all members of the interdisciplinary team present. The end result of this innovative intervention has undoubtedly improved quality of care.

Table 1. Delirium screening pre and post intervention

\begin{tabular}{|l|ll|}
\hline Delirium screening pre-intervention & $\begin{array}{l}\text { No systematic screening of patients for delirium } \\
\text { No validated tool used to screen for delirium } \\
\text { Subjective criteria such as agitation and lack of cooperation } \\
\text { used to consider whether or not the patient was delirious }\end{array}$ \\
\hline Delirium screening post-intervention & $\begin{array}{l}\text { Validated tools used to assess patient's level of sedation and } \\
\text { to detect delirium } \\
\text { Patients' level of sedation screened with the RASS scale } \\
\text { The four key features of delirium: fluctuation in mental } \\
\text { status, inattention, disorganized thinking, and altered level } \\
\text { of consciousness systematically assessed using the } \\
\text { CAM-ICU }\end{array}$ \\
\hline
\end{tabular}

\section{Discussion and recommendations for practice}

The student who led the project is an Emergency Room nurse pursuing undergraduate nursing studies. This internship had objectives similar to a previous stage done in the same ICU. In order to create a new learning experience, the Clinical Nurse Specialist encouraged the student to lead a project consisting in the implementation of an evidence-based practice initiative. This represents a very stimulating learning strategy for students who are already licensed nurses. Overall, the activity contributed to significantly enrich his nursing experience and foster the development of new skills that are inherent to the nurse clinician's role. This kind of internship benefits the nursing unit as it facilitates the implementation and follow-up of evidence based initiatives. Key elements that contributed to the success of this stage are: the ICU staff recognized that the detection and the management of delirium was problematic; the ICU clinicians acknowledged that delirium was associated with an increased risk of morbidity and mortality; the CNS, the NEC and two Intensivists had been instrumental in publicizing this new learning activity. Thus, staff buy-in to get involved in the learning activity was facilitated.

Delirium affects up to $87 \%$ of critically ill ICU patients ${ }^{[10]}$. A multitude of risk factors can contribute to the incidence and severity of delirium. Among these risk factors, some are predisposing and some are precipitating factors ${ }^{[2,22,23,26,45,46]}$. Although the exact pathophysiology of delirium is still unclear ${ }^{[18]}$, its effects on a patient's cognitive functions are

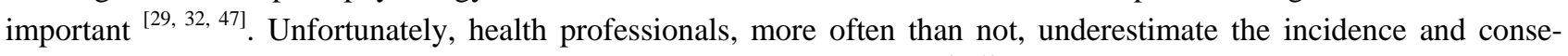
quences of delirium on patients and families, leading to suboptimal care ${ }^{[36,48]}$.

The implementation of a standardized screening tool for delirium is an important change in practice. In fact, the staff should no longer rely on their subjective evaluation to identify if a patient is suffering, or not, from delirium. The utilization of a validated tool allows the identification of patients suffering from hypoactive delirium, which is often undiagnosed by traditional subjective screening methods. Many patients can present delirium but the type of delirium and their risk factors will determine which interventions are appropriate based on clinical situation. It is of utmost importance that preventative measures and interventions be tailored to the patient's clinical situation. Furthermore, care plans should be developed with the interdisciplinary team in order to offer optimal care. Moreover, it is also essential to seek expert advice when situations are more challenging. Finally, many authors have also highlighted the importance of having a strong educational program to ensure adequate identification of risk factors, accurate assessments and an optimal care plan ${ }^{[3,20,35]}$.

Unfortunately, it was not possible for the student to collect statistics on the incidence of delirium pre and post intervention. However, nurses acknowledged that the incidence of delirium was higher than what they initially thought. Delirium 
incidence should be part of an ICU quality indicator report card. The clinicians reported to be more sensitive to the risk factors of delirium. It would be interesting, in a future study, to correlate the incidence of delirium on the unit with the risk factors presented by patients. Furthermore, it would be pertinent for graduate students to study the effectiveness of preventive strategies used by clinicians when patients present risk factors for delirium. Also, it would be interesting to examine if the clinicians used different strategies to intervene with patients presenting hypo versus hyper active delirium. Finally, it would also be relevant to correlate the incidence of complications such as ventilator acquired pneumonia and disruption of therapies that can be attributed to delirium. Such studies could potentially identify areas of practice that still require improvement.

\section{Conclusion}

Having a nursing student lead an evidence-based practice change during an internship, in collaboration with key players, can be beneficial for both the student and the clinical unit. Educational activities related to delirium are important in order to provide optimal care. This innovative project of implementing sedation and delirium scales, as well as some interventions to prevent and treat delirium, has enabled the nursing student to deepen his nursing practice, enhance his knowledge, acquire new competences, and master skills essential to the nurse clinician's role. In order to improve quality of care for the ICU patient population, the interdisciplinary team members have a key role to play. Being present at the bedside on a 24 hours basis, the nurse can have a significant impact on patient care. It is of greatest importance for all team members to work in close collaboration and to identify patients who present risk factors for delirium and put in place the appropriate interventions to prevent the development of delirium. Promptly identifying patients presenting with delirium and implementing the appropriate interventions is also essential to reduce morbidity, mortality and enhance quality of care. Family members can also play a significant role in preventing and treating delirium and should be involved in care, whenever possible. Finally, this project was not a research project. It would be pertinent for graduate students to study the presence of risk factors for delirium in patients and analyze the interventions put into practice in the clinical setting. Also, it would be interesting to identify the type of delirium, hypo versus hyperactive, and analyze the interventions put in practice. Important recommendations can be made, thus enhancing, once again, patient care. Finally, all new projects can increase the burden on health care professionals, especially nurses. It would also be interesting to study the elements that facilitate care for patients with delirium and difficulties encountered by nurses to ultimately decrease the burden on these health care professionals.

\section{References}

[1] McNicoll, L., Pisani, M. A., Zhang, Y., Ely, E. W., Siegel, M. D., \& Inouye, S. K. Delirium in the intensive care unit: Occurrence and clinical course in older patients. Journal of American Geriatrics Society. 2003; 51(5): 591-598. http://dx.doi.org/10.1034/j.1600-0579.2003.00201.x

[2] Ouimet, S., Kavanagh, B. P., Gottfried, S. B., \& Skrobik, Y. Incidence, risk factors and consequences of ICU delirium. Intensive Care Medicine. 2007; 33(1): 66-73. PMid:17102966 http://dx.doi.org/10.1007/s00134-006-0399-8

[3] Pun, B. T., \& Boehm, L. Delirium in the intensive care unit: Assessment and management. AACN Advanced Critical Care. 2011; 22(3): 225-237. PMid:21808158 http://dx.doi.org/10.1097/NCI.0b013e318220c173

[4] Salluh, J. I., Soares, M., Teles, J. M., Ceraso, D., Raimondi, N., Nava, V. S., et al. Delirium epidemiology in critical care (DECCA): An international study. Critical Care. 2010; 14(6): R210. PMid:21092264 http://dx.doi.org/10.1186/cc9333

[5] Thomason, J. W., Shintani, A., Peterson, J. F., Pun, B. T., Jackson, J. C., \& Ely, E. W. Intensive care unit delirium is an independent predictor of longer hospital stay: A prospective analysis of 261 non-ventilated patients. Critical Care. 2005; 9(4): R375-381. PMid:16137350 http://dx.doi.org/10.1186/cc3729

[6] Mehta, S., Burry, L., Fischer, S., Martinez-Motta, J. C., Hallett, D., Bowman, D., et al. Canadian survey of the use of sedatives, analgesics, and neuromuscular blocking agents in critically ill patients. Critical Care Medicine. 2006; 34(2): 374-380. PMid:16424717 http://dx.doi.org/10.1097/01.CCM.0000196830.61965.F1 
[7] Barr, J., Fraser, G. L., Puntillo, K., Ely, E. W., Gélinas, C., Dasta, J. F., et al. Clinical practice guidelines for the management of pain, agitation, and delirium in adult patients in the intensive care unit. Critical Care Medicine. 2013; 41(1): 263-306. PMid:23269131 http://dx.doi.org/10.1097/CCM.0b013e3182783b72

[8] Jacobi, J., Fraser, G. L., Coursin, D. B., Riker, R. R., Fontaine, D., Wittbrodt, E. T., et al. Clinical practice guidelines for the sustained use of sedatives and analgesics in the critically ill adult. Critical Care Medicine. 2002; 30(1): 119-141. PMid:11902253 http://dx.doi.org/10.1097/00003246-200201000-00020

[9] Vasilevskis, E. E., Ely, E. W., Speroff, T., Pun, B. T., Boehm, L., \& Dittus, R. S. Reducing iatrogenic risks: ICU-acquired delirium and weakness crossing the quality chasm. Chest. 2010; 138(5): 1224-1233. PMid:21051398 http://dx.doi.org/10.1378/chest.10-0466

[10] Ely, E. W., Margolin, R., Francis, J., May, L., Truman, B., Dittus, R., et al. Evaluation of delirium in critically ill patients: validation of the Confusion Assessment Method for the Intensive Care Unit (CAM-ICU). Critical Care Medicine. 201; 29(7): 1370-1379.

[11] Gesin, G., Russell, B. B., Lin, A. P., Norton, H. J., Evans, S. L., \& Devlin, J. W. Impact of a delirium screening tool and multifaceted education on nurses' knowledge of delirium and ability to evaluate it correctly. American Journal of Critical Care. 2012; 21(1): e1-11. PMid:22210704 http://dx.doi.org/10.4037/ajcc2012605

[12] American Psychiatric Association, \& American Psychiatric Association Task Force on DSM-IV. Diagnostic and statistical manual of mental disorders: DSM-IV-TR. (4th ed.). Washington, DC: American Psychiatric Association, 2000.

[13] Allen. J., \& Alexander, E. Prevention, recognition, and management of delirium in the intensive care unit.AACN, Advanced Critical Care. 2012; 23(1): 5-11. PMid:22290083 http://dx.doi.org/10.1097/NCI.0b013e31822c3633

[14] Olson, T. Delirium in the intensive care unit: Role of the critical care nurse in early detection and treatment. Dynamics. 2012; 23(4): 32-36. PMid:23342936

[15] Pun, B.T., \& Ely, E. W. The importance of diagnosing and managing ICU delirium. Chest. 2007; 132: 624-636. PMid:17699134 http://dx.doi.org/10.1378/chest.06-1795

[16] Balas, M. C., Rice, M., Chaperon, C., Smith, H., Disbot, M., \& Fuchs, B. Management of delirium in critically ill older adult patients. Critical Care Nurse. 2012; 32(4): 15-26. PMid:22855075 http://dx.doi.org/10.4037/ccn2012480

[17] Sona, C. Assessing delirium in the intensive care unit. Critical Care Nurse. 2009; 29(2): 103-105. PMid:19339452 http://dx.doi.org/10.4037/ccn2009329

[18] Francis, J., \& Young, G. B. Diagnosis of delirium and confusional states. UpToDate. 2011. Available from: http://www.uptodate.com/contents/diagnosis-of-delirium-and-confusional-states?source=search_result\&search=delirium\&select edTitle $=1 \sim 150$

[19] Peterson, J. F., Pun, B.T., Dittus, R. S., Thomason, J. W. W., Jackson, J. C., Shintani, A. K., et al. Delirium and its motoric subtypes: A study of 614 critically ill patients. Journal of the American Geriatrics Society. 2006; 54: 479-484. PMid:16551316 http://dx.doi.org/10.1111/j.1532-5415.2005.00621.x

[20] Inouye, S. K., Foreman, M. D., Mion, L. C., Katz, K. H., Coomey, L. M. Nurse’s recognition of delirium and its symptoms: comparison of nurse and researcher ratings. Archive of Internal Medicine. 2001; 161(20): 2467-2473. http://dx.doi.org/10.1001/archinte.161.20.2467

[21] Meagher, D. J., \&Trzepacz, P. T. Motoric subtypes of delirium. In Pun, B.T., \& Ely, E. W. (2007). The importance of diagnosing and managing ICU delirium. Chest. 2000; 132: 624-636.

[22] Van Rompaey, B., Elseviers, M. M., Schurmans, M. J., Shortridge-Baggett, L. M., Truijen, S., \& Bossaert, L. Risk factors for delirium in intensive care patients: A prospective cohort study. Critical Care. 2009; 13(3): R77. PMid:19457226 http://dx.doi.org/10.1186/cc7892

[23] Chang, Y. L., Tsai, Y. F., Lin, P. J., Chen, M. C., \& Liu, C. Y. Prevalence and risk factors for postoperative delirium in a cardiovascular intensive care unit. American Journal of Critical Care. 2008; 17(6): 567-575. PMid:18978241

[24] Bucerius. J., Gummert, J. F., Borger, M. A., Walther, T., Doll, N., Falk, V., et al. Predictors of delirium after cardiac surgery delirium: effect of beating-heart (off-pump) surgery. Journal of Thoracic and Cardiovascular Surgery. 2004; 127(1): 57-64. http://dx.doi.org/10.1016/S0022-5223(03)01281-9

[25] Dubois, M. J., Bergeron, N., Dumont, M., Dial, S., \& Skrobik, Y. Delirium in an intensive care unit: A study of risk factors. Intensive Care Medicine. 2001; 27: 1297-1304. PMid:11511942 http://dx.doi.org/10.1007/s001340101017

[26] Pandharipande, P., Cotton, B. A., Shintani, A., Thompson, J., Pun, B. T., Morris, J. A., Jr., et al. Prevalence and risk factors for development of delirium in surgical and trauma intensive care unit patients. Journal of Trauma-Injury Infection \& Critical Care. 2008; 65(1): 34-41. PMid:18580517 http://dx.doi.org/10.1097/TA.0b013e31814b2c4d

[27] Inouye, S. K., Zhang, Y., Jones, R. N., Kiely, D. K., Yang, F., \& Marcantonio, E. R. Risk factors for delirium at discharge: Development and validation of a predictive model. Archives of Internal Medicine. 2007; 167(13): 1406-1413. PMid:17620535 http://dx.doi.org/10.1001/archinte.167.13.1406 
[28] Pisani, M. A., Khong, S. Y., Kasl, S. V., Murphy, T. E., Araujo, K. L., \& Van Ness, P. H. Days of delirium are associated with 1-year mortality in an older intensive care unit population. American Journal of Respiratory and Critical Care Medicine. 2009; 180(11): 1092-1097. PMid:19745202 http://dx.doi.org/10.1164/rccm.200904-0537OC

[29] Girard, T. D., Jackson, J. C., Pandharipande, P. P., Pun, B. T., Thompson, J. L., Shintani, A. K., et al. Delirium as a predictor of long-term cognitive impairment in survivors of critical illness. Critical Care Medicine. 2010; 38(7): 1513-1520. PMid:20473145 http://dx.doi.org/10.1097/CCM.0b013e3181e47be1

[30] Rudolph, J. L., Inouye, S. K., Jones, R. N., Yang, F. M., Fong, T. G., Levkoff, S. E., et al. Delirium: An independent predictor of functional decline after cardiac surgery. Journal of American Geriatrics Society. 2010; 58(4): 643-649. PMid:20345866 http://dx.doi.org/10.1111/j.1532-5415.2010.02762.x

[31] Balas, M. C., Happ, M. B., Yang, W., Chelluri, L., \& Richmond, T. Outcomes associated with delirium in older patients in surgical ICUs. Chest. 2009; 135(1): 18-25. PMid:19017895 http://dx.doi.org/10.1378/chest.08-1456

[32] Ely, E. W., Shintani, A., Truman, B., Speroff, T., Gordon, S. M., Harrell, F. E., Jr., et al. Delirium as a predictor of mortality in mechanically ventilated patients in the intensive care unit. Journal of the American Medical Association. 2004; 291(14): 1753-1762. PMid:15082703 http://dx.doi.org/10.1001/jama.291.14.1753

[33] Pisani, M. A., Murphy, T. E., Van Ness, P. H., Araujo, K. L., Inouye, S. K. Characteristics associated with delirium in older patients in a medical intensive care unit. Archives of Internal Medicine. 2007; 167(15): 1629-1634. PMid:17698685 http://dx.doi.org/10.1001/archinte.167.15.1629

[34] Milbrandt, E. B., Deppen, S., Harrison, P. L., Shintani, A. K., Speroff, T., Stiles, R. A., et al. Costs associated with delirium in mechanically ventilated patients. Critical Care Medicine. 2004; 32(4): 955-962. PMid:15071384 http://dx.doi.org/10.1097/01.CCM.0000119429.16055.92

[35] Rice, K. L., Bennett, M., Gomez, M., Theall, K. P., Knight, M., \& Foreman, M. D. Nurse’s recognition of delirium in the hospitalized older adult. Clinical Nurse Specialist. 2011; 25(6): 299-311. PMid:22016018 http://dx.doi.org/10.1097/NUR.0b013e318234897b

[36] Ely, E. W., Stephens, R. K., Jackson, J. C., Thomason, J. W., Truman, B., Gordon, S., et al. Current opinions regarding the importance, diagnosis, and management of delirium in the intensive care unit: A survey of 912 healthcare professionals. Critical Care Medicine. 2004; 32(1): 106-112. PMid:14707567 http://dx.doi.org/10.1097/01.CCM.0000098033.94737.84

[37] Devlin, J. W., Fong, J. J., Howard, E. P., Skrobik, Y., McCoy, N., Yasuda, C., et al. Assessment of delirium in the intensive care unit: Nursing practices and perceptions. American Journal of Critical Care. 2008; 17(6): 555-565. PMid:18978240

[38] Steiner, L. A. Postoperative delirium. Part 2: Detection, prevention and treatment. European Journal of Anaesthesiology. 2011; 28(10): 723-732. PMid:21912241 http://dx.doi.org/10.1097/EJA.0b013e328349b7db

[39] Balas, M. C., Vasilevskis, E. E., Burke, W. J., Boehm, L., Pun, B. T., Olsen, K. M., et al. Critical care nurses’ role in implementing the “ABCDE bundle” into practice.Critical Care Nurse. 2012; 32(2): 35-38. PMid:22467611 http://dx.doi.org/10.4037/ccn2012229

[40] Inouye, S. K. Delirium in older persons. New England Journal of Medicine. 2006; 354(11): 1157-1165. PMid:16540616 http://dx.doi.org/10.1056/NEJMra052321

[41] ICU-JGH. Annual Report 2012-2013. Montreal: Jewish General Hospital, 2013.

[42] Randal, F. Sleep and recovery from critical illness and injury: A review of theory, current practice and future directions. Critical Care Medicine. 2008; 36(3): 697-705. PMid:18176314 http://dx.doi.org/10.1097/CCM.0B013E3181643F29

[43] Ely, W., \& Vanderbilt University. Confusion Assessment Method for the ICU (CAM-ICU): The Complete Training Manual. 2010.

[44] VUMC Center for Health Services Research. (2011, March 9, 2012). Using the CAM-ICU. Available from: http://www.mc.vanderbilt.edu/icudelirium/

[45] Burns, K. D., Jenkins, W., Yeh, D., Procyshyn, R. M., Schwarz, S. K. W., Honer, W. G., et al. Delirium after cardiac surgery: A retrospective case-control study of incidence and risk factors in a Canadian sample. BC Medical Journal. 2009; 51(5): 206-210.

[46] Steiner, L. A. Postoperative delirium. Part 1: Pathophysiology and risk factors. European Journal of Anaesthesiology. 2011; 28(9): 628-636. PMid:21785356 http://dx.doi.org/10.1097/EJA.0b013e328349b7f5

[47] Jackson, J. C., Gordon, S. M., Hart, R. P., Hopkins, R. O., \& Ely, E. W. The association between delirium and cognitive decline: A review of the empirical literature. Neuropsychology Review. 2004; 14(2): 87-98. PMid:15264710 http://dx.doi.org/10.1023/B:NERV.0000028080.39602.17

[48] Patel, R. P., Gambrell, M., Speroff, T., Scott, T. A., Pun, B. T., Okahashi, J., et al. Delirium and sedation in the intensive care unit: Survey of behaviors and attitudes of 1384 healthcare professionals. Critical Care Medicine. 2009; 37(3): 825-832. PMid:19237884 http://dx.doi.org/10.1097/CCM.0b013e31819b8608 